\title{
The Effectiveness of Mindfulness Meditation Program on Selected Aspects of Health Among Students of the B.Sc. in Physiotherapy, University of Colombo, Sri Lanka
}

\author{
Arunoda MKPD ${ }^{1,2 *}$, Gunathunga $\mathrm{MW}^{1}$ and Piyanee Klainin Yobas ${ }^{2}$ \\ ${ }^{1}$ Faculty of Medicine, University of Colombo, Sri Lanka \\ ${ }^{2}$ National University of Singapore, Singapore
}

Submission: August 14, 2019; Published: August 30, 2019

*Corresponding author: MKPD Arunoda, National University of Singapore, Singapore

\section{Abstract}

Background: The Mindfulness Meditation can be considered as a technique, practice or a habit which usually involves making human mind better as well as develop mental health. The benefits of the mindfulness meditation come in different forms as Psychological, Physical and social well-being.

Methods: A Quasi-experimental research design was carried out at one of the universities in Sri Lanka. A convenience sampling of undergraduate students of B.Sc. Physiotherapy students of University of Colombo, Sri Lanka was used, and participants were assigned into two groups. The experiment group received 32 and the control group received 32 Primary Mental Health Questionnaire (PMHQ) with sociodemographic data form, Meditation diary was used to collect data, were analyzed using Paired and Independent t-test.

Results: A total of 64 samples were recruited with 32 in each group. Mean age was 24.4years and most were females who showed high significant in stress management. Enhanced Satisfaction, kindness and happiness, controlling over jealousy and anger $(p<0.05)$ were showed significance in experimental group. Control group showed significance only in stress and kindness. Comparison of both groups, showed significance with improved satisfaction, kindness and happiness, reduced jealousy, stress and repentance ( $\mathrm{p}<0.05)$.Within subjects, only 9.38\% were daily meditators and less than 03 days per week were $75 \%$.Among daily meditators, increased satisfaction (p>0.05) ,happiness (p:0.0021) and kindness (p:0.0325), reduce stress level (p:0.0201) as well as jealousy (p:0.011) were more significant.

Conclusion: The results of this study have demonstrated that significant increases in most of positive factors of our mental health. Keywords: Mindfulness; Health; Selected Aspects of Mental Health; Feasibility

Abbreviations: MM: Mindfulness Meditation; PMHQ: Primary Mental Health Questionnaire; Mean d: Mean difference; AHSU: Allied Health Sciences Unit.

\section{Introduction}

According to World Health Organization, health is defined as a state of complete physical, mental and social well-being and not merely the absence of disease or infirmity. It is determined by the interaction between body, mind, consciousness and emotions (such as fear, anger, stress, jealousy, joy, excitement). Approximately $11 \%$ of the world population suffers from some kind of mental illness and emotional problems such as anger, dissatisfaction, mental stress and internal noise [1].
Mindfulness means "paying attention in a particular way: on purpose, in the present moment and non-judgmentally" meaning, being present, or having presence-Jon Kabat-Zinn [2]. He further describes that Mindfulness practice is based on the principle that only in the experience of the present moment can one accurately perceive what is really happening, when life is fully appreciated without the need to judge it, and when effective action can be taken. Interestingly, the most innovative practice of mindfulness meditation has been rooted in 


\section{Psychology and Behavioral Science International Journal}

Buddhist Vipassana (translated as insight) Meditation which encourages the cultivation of nonjudgmental, moment-to-moment awareness both during the formal meditation practice and in everyday day life [3]. In the meantime, mindfulness meditation has also been defined (thefreedictionary.com) as a form in which distracting thoughts and feelings are not ignored but instead acknowledged and observed none judgmentally as they arise in order to detach from them and gain insight and awareness. Whereas McGee [4], also describes mindfulness meditation as a "a psychological state of active passivity and creative quiescence," in which the mediator purposefully and not judgmentally pays attention to the present moment, attending to the multitude of sights, sounds, sensations, feelings, and thoughts that simultaneously present themselves to his or her awareness in each moment. According to the definition established by Hyman [5], mindfulness meditation is a friendly gesture toward us in which we take time simply to be.

Mindfulness meditation is "a psychological state of active passivity and creative quiescence" [6]. It can be considered as a technique, practice or a habit which usually involves making people's mind better and thus improving their mental health. The benefits of the Mindfulness meditation come in different forms as psychological, physical and social well-being. Jonathan Smith had expressed that "To meditate is to live simply and honestly in the world as it is" [6]. Many have suggested that meditation may enhance mental health, general wellbeing and also reduce stress, anxiety, addiction, aggression, suicidal tendency and depression. Some other studies have shown that the meditation can be helpful for the treatment of eating disorders, chronic medical illnesses including chronic pain, insomnia and hypertension. This may be caused by enhancing immune function which promotes brain longevity, plasticity, and learning. Meditation may enhance perceptual receptivity, openness and discrimination, decrease reaction times, and improve problem-solving ability, self-awareness, happiness, equanimity and increase psychological differentiation [6].

Among further benefits of meditation include the life with more joyful, grateful and hopefulness with satisfaction. In addition, life will reach for greater sense of well-being by understanding; acceptance and the ability to correct or repair unpleasant mood states and reduce negative mood states. In physical health, mindfulness meditation helped patients recover from Rheumatoid arthritis, Psoriasis, Chronic Low back pain, Attention, Hyperactivity disorder, myocardial ischemia, irritable bowel syndrome [4].

It is also determined by the interaction between body, mind, consciousness and the thoughts, which are coming to the mind, carry fear, anger, stress, jealousy, joy, excitement. However, these thoughts change the mood, concentration, thinking skills, and alertness of people as psychological effects. So, they also influence physical changes such as pulse, blood pressure, breathing, digestion and absorption [7]. The term Satisfaction can be broadly explained as the contentment one feels when one has fulfilled a desire, need, or expectations, Ventegod Merrick and Andersen (2003) whereas the Oxford dictionary explains it as meeting the expectations or desires [8].

\section{Feasibility}

Among number of authors who have conducted studies to investigate the feasibility of using mindfulness meditation programmes Zgierska (2007), Zylowska, et al. (2007) \& Greco, et al. (2006) are few who found positive outcomes and declared that the use of mindfulness meditation programme was feasible. However, the conditions which the intervention addressed had been different across studies. One study use mindfulness meditation programme (Zgierska, 2007) to prevent alcohol relapse while the other two studies (Zylowska, et al. 2007\& Greco, et al. 2006) use it in Attention deficit hyperactivity disorder and chronic low back pain respectively. Though their own studies had not directly addressed regarding the feasibility of mindfulness meditation programme, Zeidan, et al. (2010), Justo (2009), Shapiro, et al. (1998) and Speca et al. [9] also have been able to find higher response rates in their studies on interventions of mindfulness.

\section{Research on Mindfulness Meditation Among Students and Professionals}

As mentioned in the previous sections, researchers from many countries had been engaged in various studies to seek out the effects of mindfulness meditation among various populations. Some of these studies were to explore these objectives with professionals and students from different disciplines. One such is the study done by Lehrer $\mathrm{P}$, et al. [10] which is a randomized controlled trial, examining the effects of a 1-month mindfulness meditation versus somatic relaxation training as compared to a control group in 83 students. In this sample of 16 men and 67 women with a mean age of 25 , psychological distress, positive states of mind, distractive and ruminative thoughts and behaviors, and spiritual experience were measured, while controlling for social desirability. According to the obtained Results, significant decrease has been present in both meditation and relaxation groups, in distress as well as increases in positive mood states over time, compared with the control group ( $\mathrm{p}<.05$ in all cases). Nevertheless, there had not been any significant differences between meditation and relaxation on distress and positive mood states over time. Effect sizes for distress were large for both meditation and relaxation (Cohen's $\mathrm{d}=1.36$ and .91 , respectively), whereas the meditation group has shown a larger effect size for positive states of mind than relaxation (Cohen's $\mathrm{d}=.71$ and .25 , respectively). The meditation group has also demonstrated significant prepost decreases in both distractive and ruminative thoughts/behaviors compared with the control group ( $\mathrm{p}<.04$ in all cases; Cohen's $\mathrm{d}=.57$ for rumination and .25 for distraction for the meditation group). Consequently, Authors suggest mindfulness meditation or somatic relaxation reduces distress and improves positive mood states and mindfulness meditation may also be specific in its ability to reduce distractive and ruminative thoughts and behaviors, and this ability may provide a unique mechanism by which mindfulness meditation reduces distress.

In another report [11] based on "Interpersonal Mindfulness Training (IMT) for well-being" with 21 undergraduates for 6 weeks of duration, which aimed to reduce stress and enhance interpersonal wellbeing. The Results suggested that IMT with psychology graduate students is a feasible intervention that positively affects mindfulness, perceived stress, social connectedness, emotional intelligence, and anxiety. 
The active practice of mindfulness has been shown to increase self-efficacy [12], self-compassion [13] and empathy. Along with these implications Mayand and 0'donovan [14] has also found significant correlation with the professional lives of the Psychotherapist with mindfulness meditation. They have conducted a study aiming to explore the relationships between mindfulness, therapist well-being, and work related variables, job satisfaction and burn-out. All these three aspects have been positively increased and decreased accordingly in meditation group of therapists. Hyman [5] has furthermore described that mindfulness meditation is also useful in reducing the stress levels of the lawyers who undergo a stressful daily practice with the clients.

\section{Effectiveness of Mindfulness Meditation on Stress}

Speca, et al. [9] has conducted a randomized controlled clinical trial in a sample of cancer patients in the object of assessing the effects of participation in a mindfulness meditation-based stress reduction program on mood disturbance and symptoms of stress. Ninety patients had completed the study the mean pre-intervention scores on dependent measures had been equivalent between groups. But after the intervention, patients in the treatment group have had significantly lower scores on Total Mood Disturbance and subscales of depression, anxiety, anger, and confusion and more vigor than control subjects. The treatment group also has had fewer overall symptoms of stress; fewer cardiopulmonary and gastrointestinal symptoms; less emotional irritability, depression, and cognitive disorganization; and fewer habitual patterns of stress. Overall reduction in Total Mood Disturbance has been $65 \%$, with a 31\% reduction in Symptoms of Stress. Thus, the authors have successfully concluded that the program was effective in decreasing mood disturbance and stress symptoms in both male and female patients with a wide variety of cancer diagnoses, stages of illness, and ages.

Similar study has been carried out by Kabat-Zinn, et al. [2] with moderate to severe psoriasis patients to test the hypothesis that stress reduction methods based on mindfulness meditation can positively influence the rate at which psoriasis clears in patients undergoing phototherapy or photo chemotherapy treatment. Thirty-seven patients with psoriasis who had undergone ultraviolet phototherapy (UVB) or photo chemotherapy (PUVA) had been assessed in this study. Patients had been assigned random lying two groups and one group has been guided by mindfulness meditation-based stress reduction intervention by audio taped instructions during light treatments, while the control condition consisting of the light treatments along with no taped instructions. According to the obtained results researchers have confirmed that a brief mindfulness meditation-based stress reduction intervention delivered by audio tape during ultraviolet light therapy can increase the rate of resolution of psoriatic lesions in patients with psoriasis.

In another study carried out in a university setting in West Virginia to determine if participation in a Wellness-Based Mindfulness Stress Reduction intervention, Kolar, et al. (1999) the authors had found that effect of daily hassles, psychological distress, and medical symptoms were decreased.

Design has been a randomized controlled trial of a stress reduction intervention with a 3-month follow-up. 103 adults were the total par- ticipants, with 59 in the intervention group and 44 in the control group. $85 \%$ of subjects completed the intervention and $59 \%$ and $61 \%$ of the intervention and control subjects completed the study, respectively. The intervention consisted of an 8-week group stress reduction program in which subjects learned, practiced, and applied "mindfulness meditation" to daily life situations. The control group received educational materials and was encouraged to use community resources for stress management. The daily stress was inventory assessed the effect of daily hassles, the Revised Hopkins Symptom Checklist measured psychological distress, the Medical Symptom Checklist measured number of medical symptoms, and a Follow-up Questionnaire measured program adherence. Intervention subjects have reported significant decreases from baseline in effect of daily hassles (24\%), psychological distress, (44\%), and medical symptoms (46\%) that were maintained at the 3-month follow-up compared to control subjects (repeated measures analysis of variance [ANOVA]; $\mathrm{p}<.05$ ). Accordingly, researchers have confirmed that Self-selected community residents can improve their mental and physical health by participating in a stress reduction intervention offered by a university wellness program.

Out of the above studies, only Zeidan et al. (2010) has considered the effectiveness of brief mindfulness meditation programme while the other studies have been considered the effectiveness of long term mindfulness meditation programme. Though all studies interpret a same result the scales used in the studies had been different from each study. Moreover, researches had been continued to evaluate the effects of Mindfulness on relationship enhancement in couples, James, et al. (2002) and had been able to attain interesting positive results favorably impacting couples' levels of relationship satisfaction, autonomy, relatedness, closeness, acceptance of one another, and relationship distress; and beneficially affecting individuals' optimism, spirituality, relaxation, and psychological distress.

\section{Effects of mindfulness meditation on Satisfaction}

There are very few studies regarding the effects of mindfulness meditation on satisfaction. In one such study conducted by Majumdar (2002) he has found that there is an increase in satisfaction with life three month following mindfulness meditation programme. Here the researcher used standard questionnaire to assess the level of satisfaction with life.

\section{The Current Study}

This study aimed to determine the effectiveness of mindfulness meditation programme on selected aspects of health among the university students at a university in Sri Lanka.

And the specific objectives are:

i. To study the feasibility of using mindfulness meditation program on promotion of selected aspects of health.

ii. To find out the prominent types of mental health states, which the Mindfulness meditation program is most effective.

iii. To investigate the participation level of meditation programme among male and female students at AHSU. 
iv. To identify the effectiveness with the time duration, engage with the meditation.

\section{Methods}

\section{Research Design and Sample}

A Quasi-experimental design was carried out and a convenience sample was used Eligible criteria included being an undergraduate student who were enrolled at the university without any long term leave. Those who were suffering from a major physical or psychological illness were excluded.

\section{Data collection Procedure}

All participants were briefed about the study and informed written consent was also obtained from each participant. All participants were briefed about the study at the beginning. Information sheets were distributed among them to inform about the purpose of the study, voluntary participation, and duration of the study, participants' responsibilities and the potential benefits of the study. Informed written consent was also obtained from each participant.

Then they were provided with Primary Mental Health Questionnaire (PMHQ) [15] which consisted of two parts, socio-demographic data form and the questionnaire. The questionnaire was self-administered, and it took about 20 minutes to complete. Thirty two students consented were enrolled to the mindfulness meditation program for 03 months of duration between August 2011 and November 2011.During that time period, they were provided a meditation diary to record the duration of meditation. At the end of November, the effectiveness of the Mindfulness meditation program was evaluated by re-administering the above questionnaire again.

\section{The Intervention}

According to Gunathunga MW [15], Meditation technique which was used in this research is as follows;

The practitioner is asked to consider 25 parts of the body i.e., head, forehead, right eye, nose, left eye, right cheek, left cheek, mouth, chin, neck, upper chest, lower chest, upper abdomen, lower abdomen, right thigh, right knee, right lower leg, right foot, right toes, left thigh, left knee, left lower leg, left foot and left toes. The practitioner takes his mind to one part at a time and contemplates "may all be well, happy and peaceful" and goes on to the next part and contemplates the same thing. He does this for all 25 parts from head to the toes of the left leg and re-starts from the head. This method trains the mind to let go of the attachment to those body parts using loving kindness as a tool for doing it. When he starts feeling pain in various parts of the body, because of being without changing posture, he contemplates "may all be well, happy and peaceful" three times. If he feels pain elsewhere, he wishes the same to that part too. Whether the pain subsides or not, he gets back to the contemplation of the body.

The main objective is to determine the effectiveness of Mindfulness meditation (MM) program in selected aspects of health among students of B.Sc. physiotherapy. Study feasibility, Gender difference in participation, relationship with the time and differences between study group and control group were other objectives. All participants were briefed about the study at the beginning. Information sheets were distributed among them to inform about the purpose of the study, voluntary participation, and duration of the study, participants' responsibilities and the potential benefits of the study. Informed written consent was also obtained from each participant.

Then they were provided with Primary Mental Health Questionnaire (PMHQ) [15] which consisted of two parts, socio-demographic data form and the questionnaire. The questionnaire was self-administered, and it took about 20 minutes to complete. Thirty-two students consented were enrolled to the mindfulness meditation program for 03 months of duration between August 2011 and November 2011.During that time period, they were provided a meditation diary to record the duration of meditation. At the end of November, the effectiveness of the Mindfulness meditation program was evaluated by re-administering the above questionnaire again.

\section{Measures}

\section{The Questionnaire}

The questionnaire was administered by Gunathunga et al. [15]. This study used self-administered questionnaire to collect data, which took about 20 minutes to complete. The Primary Mental Health Questionnaire (PMHQ) which consisted of two parts. Gunathunga et al. [15]. Part one included socio-demographic data form that was used to collect data such as age, religion, university details and day today religious activities. Part two included questions to assess the mental health status on an eleven point scale which was based on primary aspects of mental health. The questionnaire was self-administered, and which was pre-tested among a batch of new entrants to a university by Gunathunga et al. [15]. Gunathunga,, et al, Primary Mental Health Questionnaire (PMHQ)"poster (abstract) 13th Annual Academic Sessions of the College of Community Physicians of Sri Lanka.2008 Sept.17th-20th Colombo.) Furthermore, meditation diary was used to record the duration of meditation which is created by the researcher.

\section{Contents of the PMHQ}

The PMHQ consists of 11 individual questions with numerical scale format which is based on some aspects of mental health. They were,

i. Satisfaction-The first 03 questions of the questionnaire were related to measure satisfaction about money, food and cloths.

ii. Kindness

iii. Jealousy

iv. Stress

v. Anger level

vi. Repentance

vii. Happiness

viii. Meditation diary-This was used to record the duration of time period engaged in MM Program which was created by the researcher. 


\section{Data Analysis}

A statistical analysis was done for the collected data by the statistical package SPSS 17.0 (Statistical Package for Social Sciences) stored in household personal computer. The participants were divided into 02 groups with thirty two in each group as meditators (study group) and non-meditators (control group). The mean scores in the sample for 11 questions with numerical analog scale were calculated and the socio-demographic characteristics as age, sex, religion, university entrance were analyzed using simple descriptive statistics. The difference of the values in the pre and post tests for the selected aspects of mental health among experimental group and the control group, relationship of time period engaged in meditation were analyzed using 'T-test'. Paired sample T-test was used to assess any significant different between mean values of the variables in same group and both groups were compared using Independent sample T- test [16-21].

\section{Results}

\section{Demographic Characteristics of the Participants}

Consent was sought from 135 students of the Allied Health Sciences Unit (AHSU) to participate in the study. Of them, 32 consented to meditate and enrolled in the study. 32 participants were selected from others according to the convenient sampling method. Being a student in AHSU and not on any long term leave were inclusion criteria. Those who were suffering from a major physical or psychological illness were excluded.

Among all students of the unit, only 32 subjects consented to meditate and enrolled in the study. It was nearly $25 \%$ of response rate. So, this was a considerably less response rate and it would be the major limitation in my study.

Consent was sought from 135 students of the B.Sc. Physiotherapy, Allied Health Sciences Unit (AHSU), Faculty of Medicine, and University of Colombo. Of them, 32 consented to meditate and enrolled in the study. 32 participants were selected from others according to the convenient sampling method. Thirty two students consented were enrolled to the mindfulness meditation program for 03 months of duration between August 2011 and November 2011.During that time period, they were provided a meditation diary to record the duration of meditation. At the end of November, the effectiveness of the Mindfulness meditation program was evaluated by re-administering the above questionnaire again- Study subjects mean age was 24.4(+-0.8) years. Most of the participants were female $(60 \%)$ and Buddhists. Most of them were $2006 \mathrm{~A} / \mathrm{L}$ batch students (Table 1).

Table 1: Predisposing socio-demographic characteristics $(n=64)$.

\begin{tabular}{|c|c|c|c|c|}
\hline \multirow{2}{*}{ Characteristics } & \multicolumn{2}{|c|}{ Intervention $(n=32)$} & \multicolumn{2}{|c|}{ Control(n=32) } \\
\hline & Frequency & Percentage & Frequency & Percentage \\
\hline \multicolumn{5}{|l|}{ Gender } \\
\hline -Male & 13 & $40.6 \%$ & 11 & $34.4 \%$ \\
\hline -Female & 19 & $59.4 \%$ & 21 & $65.6 \%$ \\
\hline \multicolumn{5}{|l|}{ Religion } \\
\hline -Buddhism & 30 & $93.7 \%$ & 22 & $68.7 \%$ \\
\hline -Catholic & 02 & $6.3 \%$ & 08 & $25.0 \%$ \\
\hline -Hindu & - & - & 02 & $6.3 \%$ \\
\hline -Islam & - & - & - & - \\
\hline \multicolumn{5}{|c|}{ Year of University Entrance } \\
\hline$-2005 \mathrm{~A} / \mathrm{L}$ & 02 & $6.3 \%$ & 03 & $9.4 \%$ \\
\hline$-2006 \mathrm{~A} / \mathrm{L}$ & 15 & $46.7 \%$ & 11 & $34.4 \%$ \\
\hline$-2007 \mathrm{~A} / \mathrm{L}$ & 03 & $9.4 \%$ & 05 & $15.6 \%$ \\
\hline$-2008 \mathrm{~A} / \mathrm{L}$ & 12 & $37.6 \%$ & 13 & $40.6 \%$ \\
\hline Age & \multicolumn{2}{|c|}{ Mean } & \multicolumn{2}{|c|}{$24.4(+-0.8)$} \\
\hline
\end{tabular}

The Difference of the Mean Values (Mean d) in the Pre and Post Tests for the Selected Aspects of Mental Health among Male and Female Groups

With regard to gender difference in mindfulness, Table 2 showed significant improvement of males in reducing jealousy (-1.46) anger
$(-0.85)$, repentance $(-0.77)$ and developing some positive mind aspects like satisfaction $(0.321,0.652)$, kindness (1.15) and happiness (1.44). But in females, Stress management(-0.89) was higher than in male subjects after engaging in MM program. According to my study that shown in the above table, most of the negative aspects of mental health (jealousy, anger, repentance) were managed in males than female subjects. 


\section{Psychology and Behavioral Science International Journal}

Table 2: Mean differences between male and female subjects.

\begin{tabular}{|c|c|c|}
\hline Variables & Mean d & Mean d $_{\text {(Male) }}$ \\
\hline Satisfaction about money & 1.02 & 0.321 \\
\hline Satisfaction about food & 0.235 & 0.652 \\
\hline Satisfaction about cloths & 0.752 & 0.148 \\
\hline Kindness & 1.05 & 1.15 \\
\hline Jealousy & -1.05 & -1.46 \\
\hline Stress & -0.89 & -0.61 \\
\hline Anger & -0.63 & -0.85 \\
\hline Repentance & -0.63 & -0.77 \\
\hline Happiness & 1.27 & 1.44 \\
\hline
\end{tabular}

Table 3: Mean difference and ' $p$ value' for Experimental group.

\begin{tabular}{|c|c|c|}
\hline Variables & Mean d & P value \\
\hline Satisfaction about money & 1.0625 & 0.0051 \\
\hline Satisfaction about food & 0.6875 & 0.0154 \\
\hline Satisfaction about cloths & 0.6250 & 0.0345 \\
\hline Kindness & 1.0937 & 0.0162 \\
\hline Jealousy & -1.2187 & 0.0442 \\
\hline Stress & -0.3125 & 0.1012 \\
\hline Anger & -0.7187 & 0.0040 \\
\hline Repentance & -0.6875 & 0.0560 \\
\hline Happiness & 1.3754 & 0.0030 \\
\hline Willingness to meditate & & 0.0234 \\
\hline
\end{tabular}

The Difference of the Values in the Pre and Post Tests for the Selected Aspects of Mental Health among Experimental Group

As illustrated in Table 3, enhanced Satisfaction, kindness and happiness, controlling over jealousy and anger $(\mathrm{p}<0.05)$ were some of the factors that showed significance in experimental group. Further desire to engage in MM program showed considerable significance. But, repenting level was not in a significantly different (p: 0.056)

The Difference of the Values in the Pre and Post Tests for the Selected Aspects of Mental Health Among Control Group

Table 4 describes, in the control group that showed significance only in stress (p: 0.001) and kindness (p: 0.002). Rest of factors are less significant.

Table 4: Mean difference and ' $p$ value' for Control group.

\begin{tabular}{|c|c|c|}
\hline Variables & Mean d & P value \\
\hline Satisfaction about money & 0.6250 & 0.053 \\
\hline Satisfaction about food & 0.2187 & 0.325 \\
\hline Satisfaction about cloths & 0.6875 & 0.105 \\
\hline Kindness & 1.1562 & 0.0024 \\
\hline Jealousy & 0.625 & 0.804 \\
\hline Stress & -0.625 & 0.001 \\
\hline Anger & 0.4062 & 0.196 \\
\hline Repentance & -0.6562 & 0.072 \\
\hline
\end{tabular}

The Difference of the Values in the Pre and Post Tests for the Selected Aspects of Mental Health Among Experimental and Control Group

Table 5 showed pre-post effects were statistically significant. Comparison of both groups after 03 months that showed significance with some factors such as improved satisfaction, kindness and happiness, reduced jealousy, stress and repentance( $\mathrm{p}<0.05)$. Based on results it reveals less significance with anger (p: 0.321)

\section{The Relationship of the Duration of Time Period Engaged in Mm Program}

The duration of time period engaged in MM program,less than 03 days per week is $75 \%$ and $9.38 \%$ are daily meditators. $15.63 \%$ for more than 03 days per week (Figure 1). 


\section{Psychology and Behavioral Science International Journal}

\begin{tabular}{|c|c|c|}
\hline Happiness & 1.1562 & 0.0501 \\
\hline Willingness to meditate & 08521 & 0.1550 \\
\hline
\end{tabular}

Table 5: Mean difference and ' $p$ value' for both groups.

\begin{tabular}{|c|c|c|}
\hline Outcome Variables & Mean $_{\mathrm{d}(\mathrm{E})}$ & Mean $_{\mathrm{d}(\mathrm{C})}$ \\
\hline Satisfaction about money & 1.0625 & 0.6250 \\
\hline Satisfaction about food & 0.6875 & 0.2187 \\
\hline Satisfaction about cloths & 0.6250 & 0.6875 \\
\hline Kindness & 1.0937 & 1.1562 \\
\hline Jealousy & -1.2187 & 0.0625 \\
\hline Stress & -0.3125 & -0.6250 \\
\hline Anger & -0.7187 & 0.4062 \\
\hline Repentance & -0.6875 & -0.6562 \\
\hline Happiness & 1.3750 & 1.1562 \\
\hline
\end{tabular}

Mean $d(E)$ : Mean difference between pre and post tests of the Experimental group.

Mean $\mathrm{d}(\mathrm{C})$ : Mean difference between pre and post tests of the Control group.

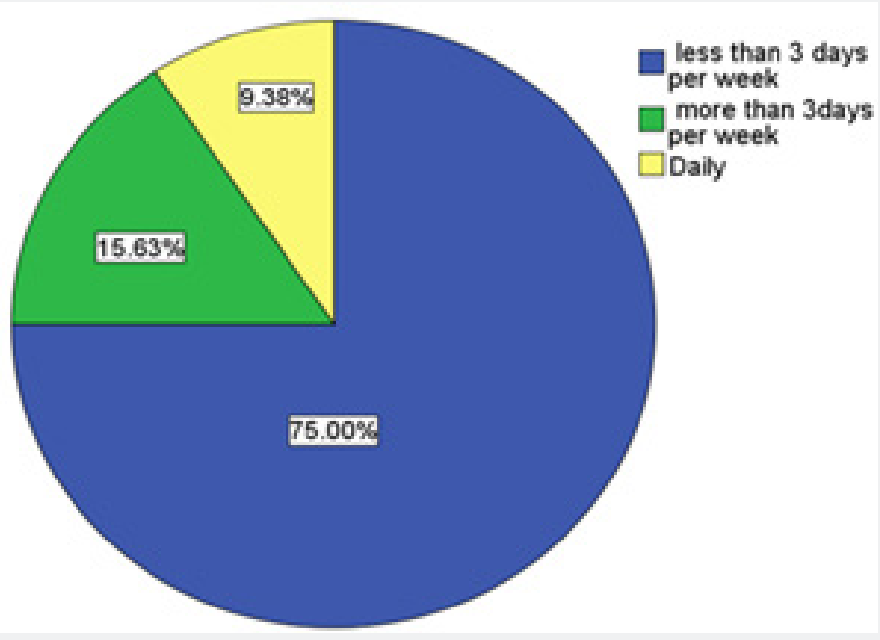

Figure 1: Distribution of the students with the time engaged in meditation.

As illustrated in Table 6, extension of engaged time in meditation have significant effect on many factors in questionnaire, increased satisfaction( $p>0.05$ ), happiness ( $p: 0.0021)$ and kindness (p:0.0325), re- duce stress level (p:0.0201) as well as jealousy (p:0.011) were some factors. It was not shown in a significant difference of controlling anger and repentance.

Table 6: Mean difference and ' $p$ value' for Control group.

\begin{tabular}{|c|c|c|c|}
\hline Aspects of PMHQ & Mean $_{\mathrm{d}(\text { daily })}$ & Mean $_{\mathrm{d}(<3 \text { days/wk) }}$ & P value \\
\hline Satisfaction-money & 1.00 & 1.8 & 0.04521 \\
\hline Satisfaction-food & 1.33 & 0.4 & 0.0021 \\
\hline Satisfaction-cloths & 0.66 & 0.4 & 0.3254 \\
\hline Kindness & 3.67 & 0.8 & 0.0235 \\
\hline Jealousy & 2.66 & 1.2 & 0.0453 \\
\hline Stress & -1.34 & -1.4 & 0.0023 \\
\hline Anger & 1.33 & 1.4 & 0.5236 \\
\hline Repentance & -4.67 & -1.6 & 0.0523 \\
\hline Happiness & 0.67 & 0.8 & 0.0455 \\
\hline
\end{tabular}




\section{Discussion}

\section{Feasibility of Study Population Regarding MM Program}

As this study was a quasi-experimental design which should practiced by each participant, only 32 subjects consented to meditate and enrolled in the study. It was nearly $25 \%$ of response rate. This was a considerably less response rate compared to Zeidan et al (2010), Speca, et al [9] studies, although they had carried out this MM program to assess different aspects.

Higher participation number of females $(60 \%)$ showed higher feasibility in my study, whereas a study carried out by Mendelson T et al (2010) with school children showed similar number of higher participation of females $(60.8 \%)$ in their study. According to the results, it would be further beneficial by increasing the duration of practice more than 03 months and least number of the daily meditators was the other problem. Compared to time periods of other research articles, 03 months of time period is not sufficient to obtain expected results in individuals whereas study participants to engage in their academic workload.

\section{To study effectiveness MM Program among Males and Fe- males}

As this study recruited both male and female students in same educational category, effect of meditation on these two groups was assessed. Generally, both male and female subjects had shown improvement in almost all the variables indicating effectiveness of meditation. With regard to gender difference in mindfulness, it showed significant improvement of males in reducing jealousy (-1.46), anger $(-0.85)$, repentance $(-0.77)$ and developing some positive mind aspects like satisfaction $(0.321,0.652)$, kindness $(1.15)$ and happiness (1.44). Similar results had been shown in Saucier E A (2011) in his study. It revealed considerable improvement in control of Jealousy and Anger in males than females. This may be due to increased opportunities for male students to take part in group activities and achievements rather than working as individuals in university career. In my study, both males $(-0.89)$ and female $(-0.61)$ participants showed improvements in management of stress. However, females (-0.89) have shown positive response for this. In contrast to this result, saucier E A (2011) suggested that women get more stressed. Further, he had explained that this would be due to premenstrual tension and the other external factors. However, the reason for deviation of this result may be due to psychological support and better understanding of stress management that are using from the beginning of the B.Sc Physiotherapy degree program in Behavioral Sciences Stream (BSS).The male participants had showed positive response in factor kindness and same study done by Saucier E A (2011) revealed that males got significant enhancement of kindness in his study.

\section{Investigate the Effectiveness of MM Program among Medita- tors and Non-Meditators}

According to the results, it revealed significant difference in almost all factors in experimental group after 03 months, although control group had shown significant relationship in some aspects. Both groups had given general understanding related to the methodology of the study. Therefore, this may have affected on responses of control group after 03 months. This was a weakness point of this study design.

Enhanced Satisfaction, kindness and happiness, controlling over jealousy and anger $(p<0.05)$ were some of the factors that showed significance in experimental group. Further desire to engage in MM program showed considerable significance. This suggests effectiveness and improved desire towards MM program and need of further guidance.

In control group, that showed significance only in stress and kindness. It may be due to better follow-up of BSS in our university as mentioned above. Comparison of both groups (Table 5) after 03 months of the program, showed significance with some factors such as improved satisfaction, kindness and happiness, reduced jealousy, stress and repentance $(p<0.05)$. Based on results it reveals less significance with anger (p: 0.321). Kolar, et. al (1999) had showed on a study, with 59 in the intervention group and 44 in the control group, Intervention subjects have reported significant decreases of Stress. Another study conducted by Majumdar (2002),which is based on the effectiveness of MM on Satisfaction among both groups, that shows high significance in experimental group.

\section{Evaluate the Effect of Enrolled Time Period with MM Pro- gram}

Literature states that enrolled time affects to effectiveness of MM programe. According to this study except three male participants, others had not practiced any type of meditation earlier. Therefore ' $p$ values' for each factor for each time period prior to study does not indicates significance whereas it showed significance after three months in 2nd assessment. 03 participants who had followed MM program daily, had shown well demarcated results in exams, participation in extra-curricular activities as well as improved creativity. (Although this was beyond scope of my study) This shows that, extension of engaged time in meditation have significant effect on many factors in questionnaire ,increased satisfaction(p>0.05) ,happiness ( $p: 0.0021)$ and kindness (p:0.0325), reduce stress level (p:0.0201) as well as jealousy(p:0.011) were some factors. Most of them had not practiced that more than 20 minutes per day.

Compared to time periods of other research articles, 03 months of time period is not sufficient to obtain expected results in individuals whereas study participants to engage in their academic workload. Lindon (1973) had carried out a study by using mindfulness meditation program practice for 20 minutes twice daily over 18 weeks to detect the effectiveness among school children.

\section{Study limitations}

The sample size was small; hence, it was not able to detect a large range and a variety of responses. Since, the study participants were from various batches, it was really difficult to follow-up the students. Further, exams and vacations were overlapped, because of that reason.

Among all students of the unit, only 32 subjects consented to meditate and enrolled in the study. It was nearly $25 \%$ of response rate. So, 
this was a considerably less response rate and it would be the major limitation in my study.

\section{Conclusion}

The present study focusses on the identification of the effectiveness of the Mindfulness Meditation (MM) Program on selected aspects of Health among B.Sc. Physiotherapy students. There are important points to be highlighted from this study regarding the results. The results of this study have demonstrated that significant increases in most of positive factors of our mental health among male subjects, although a greater part of the sample is females. Further, daily meditators have shown great effectiveness from this MM program. My study concludes that MM program is effective in significantly reducing Stress among female subjects. As women get stressed easily, this meditation method will be beneficial for all of them. However, despite all the short comings, and limitations the final outcome of the study was fairly successful to a larger extend.

\section{Recommendations}

According to the results, there is higher effectiveness of MM programme among students. So, those who want to practice further can be referred to appropriate trainers of meditation. Every day follow-up is very essential, and it will be more beneficial for their academic work as well.

\section{Ethical Approval}

This study was approved by the Ethical Review Committee of the Faculty of Medicine, University of Colombo and Allied Health Sciences Unit.

\section{Acknowledgements}

I would like to thank my supervisor Dr.M.W.Gunathunga, Senior Lecturer in Community Medicine, Faculty of Medicine, and University of Colombo with heartfelt gratitude for his guidance, advices, support and encouragement throughout. I am very grateful to the senior lecturer Prof. Piyanee Klainin Yobas, Yong Loo Lin School of Medicine, ALCNS, National University of Singapore for encouraging and giving me knowledge on publish this research article. My sincere gratitude to the senior lecturer Mrs. M.A.L.K.N. Kanthalan kathilaka, Department of Community Medicine, Faculty of Medicine, University of Colombo for giving knowledge on statistical data analysis. My special thanks go to my dear sisters of $2005 \mathrm{~A} / \mathrm{L}$ batch, for giving all the guidance and support. My sincere gratitude goes Miss. Akushla Rathnayake, Demonstrator of AHSU. At last, to all the participants in our university, for their kind cooperation and willingness to participate in my study.

\section{References}

1. World Health Organization (2010) "What is Health".

2. Kabat Zinn J (1994) Wherever you go, there you are: Mindfulness meditation in everyday life. Hyperion, New York, USA. p.4.
3. Jain S, Shapiro SL, Swanick S, Roesch SC, Mills (2003) A randomized controlled trial of mindfulness meditation versus relaxation training: Effects on distress, positive states of mind, rumination, and distraction. Annals of Behavioral Medicine 33(1).

4. Greeson JM (2009) Mindfulness Research Update: 2008. Complement Health Part Rev 14(1): 10-18.

5. Hyman JP (2007) The Mindful Lawyer: Mindfulness meditation and Law Practice.

6. McGee M (2008) Meditation and Psychiatry. Psychiatry (Edgmont) 5(1): 28-41.

7. Holzel BK, Ott U, Gard T, Hempel H, Weygandt M, et al. (2008) Investigation of Mindfulness meditation practitioners with voxel-based morphometry. Soc Cogn Affect Neurosci s3(1): 55-61.

8. Thompson D (1995) The Concise Oxford Dictionary of current English. ( $9^{\text {th }}$ Edtn.) Oxford University Press, United Kingdom pp. 525.

9. Speca M, Linda E, Carlson Goodey E, Angen M (2000) A Randomized, Wait-List Controlled Clinical Trial: The Effect of a Mindfulness Meditation-Based Stress Reduction Program on Mood and Symptoms of Stress in Cancer Outpatients. Psychosomatic Medicine 62: 613-622.

10. Lehrer P, Woolfork RL, Sime WE (2007) Principles and Practice of Stress Management.

11. Cohen JS, Miller L (2005) Interpersonal Mindfulness Training for Well-Being: A Pilot Study with Psychology Graduate Students. Teachers College Record 111(12): 2760-2774.

12. Grossman P, Niemann L, Schmidt S, Walach H (2004) "Mindfulness-based stress reduction and health benefits: A meta-analysis." Journal of Psychosomatic Research 57(1): 35-43.

13. Shapiro SL, Astin JA, Bishop SR, Cordova M (2005) Mindfulness based stress reduction for health care professional: Results from a randomized trial. J Gen Intern Med 12(2):164-176.

14. Mayand S, O'donovan A (2007) The Advantages of the Mindful Therapist. Psychotherapy in Australia 13(4): 46-53.

15. Gunathunga MW, Gunathunga CK, Perera DCJ (2008) Primary Mental Health Questionnaire (PMHQ) poster (abstract) $13^{\text {th }}$ Annual Academic Sessions of the College of Community Physicians of Sri Lanka.

16. Gunathunga MW (2010) Perfect Mental Health pp: 35-37.

17. Kabat Zinn J, Wheeler E, Light T, Skillings A, Scharf MJ (2010) Influence of a mindfulness meditation-based stress reduction intervention on rates of skin clearing in patients with moderate to severe psoriasis undergoing phototherapy (UVB) and photo chemotherapy (PUVA). Psychosom Med 60(5): 625-632.

18. Kolar KA, Reger MM, Pearson BE, Pearson JC (2010) Women's Center for Mind-Body Health. Evaluation of a Wellness-Based Mindfulness Stress Reduction intervention in West Virginia, US State.

19. Linden W (1973) Practicing of meditation by school children and their levels of field dependence-independence, test anxiety, and reading achievement. J Consult Clin Psychol 41(1): 139-143.

20. Mendelson T, Greenburg MT, Dariotis JK, Gould LF, Rhoades BL, et al. (2010) Feasibility and preliminary outcomes of a school-based mindfulness intervention for urban youth. J Abnorm Child Psychol 38(7): 985-994.

21. Saucier EA (2011) The Effect of trait Mindfulness on Acute Stress is Gender and Affect Dependent. 

(C) Commons Attribution 4.0 License
Col: $10.19080 /$ PBSIJ.2019.13.555854

\section{Your next submission with Juniper Publishers will reach you the below assets}

- Quality Editorial service

- Swift Peer Review

- Reprints availability

- E-prints Service

- Manuscript Podcast for convenient understanding

- Global attainment for your research

- Manuscript accessibility in different formats

( Pdf, E-pub, Full Text, Audio)

- Unceasing customer service

Track the below URL for one-step submission https://juniperpublishers.com/online-submission.php 